\title{
Adipokine gene variability and plasma levels in patients with chronic periodontitis -a case-control study
}

\section{Petra BORILOVA LINHARTOVA ${ }^{(a)}$ Julius JANOS(a) \\ Hana POSKEROVA(a) \\ Denisa KAVRIKOVA(a) \\ Antonin FASSMANN(a) ID \\ Ladislav DUSEK(b) \\ Lydie IZAKOVICOVA HOLLA(a)}

(a) Masaryk University, Faculty of Medicine, Clinic of Stomatology, Brno, Czech Republic.

(b)Masaryk University, Institute of Biostatistics and Analyses, Brno, Czech Republic.

Declaration of Interests: The authors certify that they have no commercial or associative interest that represents a conflict of interest in connection with the manuscript.

Corresponding Author:

Lydie Izakovicova Holla

E-mail: holla@med.muni.cz

https://doi.org/10.1590/1807-3107bor-2019.vol33.0034

Submitted: September 12, 2018

Accepted for publication: February 27, 2019

Last revision: March 19, 2019
Abstract: Specific variants in genes that encode adipokines and their mRNA and protein expression were previously studied in type 2 diabetes mellitus (T2DM) and obesity, and similar studies have been performed for chronic periodontitis (CP). The aim of this case-control study was to investigate the possible impacts of adiponectin (ADIPOQ), leptin (LEP) and its receptor (LEPR), and resistin (RETN) on the etiopathogenesis of CP. Examinations were performed on 118 non-periodontitis healthy subjects (healthy controls, HC), 205 healthy individuals with $\mathrm{CP}(\mathrm{H}+\mathrm{CP})$ and 86 type 2 diabetes patients with $\mathrm{CP}(\mathrm{T} 2 \mathrm{DM}+\mathrm{CP})$. Variants within the ADIPOQ (rs2241766, rs1501299), LEP (rs13228377, rs2167270), LEP receptor (rs1805096), and RETN (rs1862513) genes were determined by qPCR. In addition, the plasma levels of ADIPOQ, LEP, and RETN were analysed by ELISA for 80 individuals. The genotype frequencies of the SNP ADIPOQ +45G/T (rs2241766) differed between the $\mathrm{HC}$ and $\mathrm{H}+\mathrm{CP}$ groups $\left(\mathrm{p}=0.03, \mathrm{p}_{\mathrm{corr}}>0.05\right)$, and carriers of the TT genotype had a lower risk of developing $\mathrm{CP}$ compared to carriers of the GG or TG genotypes ( $p<0.01, \mathrm{p}_{\text {corr }}>0.05$ ). However, there were no significant differences in the plasma levels of ADIPOQ, LEP or RETN between the study groups ( $p>0.05$ ). Plasma levels of the adipokines were also independent of the gene profiles $(p>0.05)$. Adipokine plasma levels did not change in patients with $\mathrm{H}+\mathrm{CP} / \mathrm{T} 2 \mathrm{DM}+\mathrm{CP}$ compared to $\mathrm{HC}$, but we did identify a specific polymorphism in the ADIPOQ gene that was associated with CP. Although the ADIPOQ +45G/T (rs2241766) gene variant may be a candidate biomarker for $\mathrm{CP}$, further research is required in larger populations with different ethnic backgrounds before any final conclusions can be drawn about the role of this gene in $\mathrm{CP}$.

Keywords: Chronic Periodontitis; Diabetes Mellitus, Type 2; Adipokines.

\section{Introduction}

Chronic periodontitis (CP) affects periodontal tissues and may lead to alveolar bone destruction and tooth loss. ${ }^{1}$ A potential key step in the etiopathogenesis of this disease may be the invasion of the periodontium by periodontal pathogens and deceive host defences. ${ }^{2}$ Additionally, there is a relationship between $\mathrm{CP}$, type 2 diabetes mellitus (T2DM) and/or 
obesity, ${ }^{3,4}$ all of which are diseases associated with low-grade inflammation.

Adipocytes are the main producers of the pro-/ anti-inflammatory cytokines called adipokines. Recent studies suggest that adipokines (adiponectin, ADIPOQ; leptin, LEP; resistin, RETN) are also secreted by periodontal ligament (PDL) cells, and could be regulated by periodontal pathogens and inflammatory mediators. ${ }^{5}$ As a result, adipokines are potential candidate molecules that could account for the association between $\mathrm{CP}, \mathrm{T} 2 \mathrm{DM}$ and/or obesity. ${ }^{6}$ Two polymorphisms in the $A D I P O Q$ gene have been studied in Japanese T2DM patients with CP. In Indian population, a gene variant in the RETN gene has been associated with periodontal inflammation in both obese and non-obese patients. ${ }^{8}$ To date, no study has analysed the variability in adipokine genes in Caucasian subjects with known periodontal statuses.

A recent meta-analysis ${ }^{9}$ focused on adipokine profiles (ADIPOQ, LEP and RETN) as biomarkers in the gingival crevicular fluid (GCF) of obese and non-obese $\mathrm{CP}$ patients. Periodontitis mainly affected the circulating levels of ADIPOQ and RETN whereas obesity and periodontitis affected the circulating levels of LEP and favoured a pro-inflammatory state..$^{10}$ The meta-analysis by Zhu et al. ${ }^{11}$ found elevated serum levels of LEP and decreased serum levels of ADIPOQ in periodontitis patients compared with controls that had a body mass index $(\mathrm{BMI})<30$. Similarly, decreased plasma levels of ADIPOQ were found in patients with severe periodontitis compared with patients with mild or moderate periodontitis, independent of overweight or obese status, ${ }^{12}$ and the levels of LEP in the GCF and serum correlated with periodontal parameters. ${ }^{13}$ Nevertheless, serum levels of LEP and ADIPOQ did not significantly change after periodontal treatment in systemically healthy individuals. ${ }^{11}$ The review by Devanoorkar et al. ${ }^{14}$ provides insight into the biological action of RETN and its potential role in periodontitis and DM.

These pleiotropic adipokines may influence periodontal tissues via different mechanisms. ADIPOQ stimulates the expression of growth factors and extracellular matrix, in vitro wound healing, and proliferation. Furthermore, ADIPOQ enhances the activity of bioactive molecules, such as enamel matrix derivatives, which are critical for periodontal regeneration. ${ }^{5}$ LEP enhances the expression of matrix metalloproteinases in human gingival fibroblasts and affects bone metabolism, which may contribute to the degradation of the collagen-rich extracellular matrix and the destruction of the alveolar bone. ${ }^{15}$ A meta-analysis by Akram et al. ${ }^{9}$ suggests that monocytes and macrophages that are present in chronic periodontal disease may be the major source of RETN following stimulation by pro-inflammatory cytokines in periodontal tissues.

The effects of specific variants in genes that encode adipokines on their mRNA/protein expression were previously studied with controversial results. Nevertheless, adipokines are considered to be involved in the etiopathogenesis of $\mathrm{CP}$, and we hypothesize that an individual's adipokine gene profile may predispose the patient to this multifactorial inflammatory disease.

The aims of this study were: i) to determine six common single nucleotide polymorphisms (SNPs) in the genes that encode ADIPOQ, LEP and its receptor (LEPR), and RETN, ii) to analyse adipokine plasma levels in subgroups of systemically healthy individuals with or without $\mathrm{CP}$ and individuals with both T2DM and $\mathrm{CP}$ to investigate the possible impacts of these adipokines on the etiopathogenesis of $\mathrm{CP}$.

\section{Methodology}

The study was performed with the approval of the Committees for Ethics of the Medical Faculty, Masaryk University Brno (No. 13/2013) and the St. Anne's Faculty Hospital. Written informed consent was obtained from all participants before inclusion in the study, in accordance with the Declaration of Helsinki.

\section{Study population and clinical examinations}

In this case-control (or case-case) association study, 409 individuals from the region of South Moravia were randomly selected. Participants were recruited from the patient pool of the Periodontology Department, Clinic of Stomatology, St. Anne's Faculty Hospital Brno, from 2010 to 2017. The inclusion criteria for this study were willingness to participate, compliance with the diagnostic criteria for CP and/or T2DM, and for the control group, systemic and periodontal health. No participants were receiving treatment for 
periodontitis at the time of diagnosis, but treatment was offered to all participants following diagnosis. Similar to the patients with $\mathrm{CP}$, healthy controls were required to have at least 20 remaining teeth and be in good general health. For the DM patients, this criterion had to be relaxed because most DM patients who were willing to undergo a dental examination had significantly fewer teeth. As a result, we included all DM patients who had at least 12 of their own teeth for which the periodontal indexes could be examined so that a statistically evaluable size of the sample set could be reached. The exclusion criteria for this study were a history of systemic disease (such as coronary artery disease, malignancies, immunodeficiency disorders), current pregnancy or lactation, immunosuppression that was attributable to a medication or concurrent illness, use of antibiotics or anti-inflammatory drugs within six weeks of recruitment, and inability to consent.

The diagnosis of non-periodontitis/periodontitis was based on a detailed clinical examination, medical and dental history, tooth mobility and a radiographic assessment. Probing depth (PD) and clinical attachment loss (CAL) were measured using a UNC-15 periodontal probe at four sites for every tooth. We also investigated the plaque index (PI) according to Silness and Lö ${ }^{16}$ and the gingival index (GI) according to Lö $\mathrm{e}^{17}$, and the presence of plaque and inflammation of the gingiva were evaluated for four surfaces of each tooth (distal, vestibular, mesial, oral). The resulting values for these measurements were calculated as an arithmetic mean. All of the patients with CP fulfilled the diagnostic criteria according to their CAL levels as defined by the International Workshop for a Classification of Periodontal Diseases and Conditions for Chronic Periodontitis: ${ }^{18}$ Among these patients, $\geq 30 \%$ of the teeth were affected (generalized CP) and their PD was $\geq 4 \mathrm{~mm}$. The severity of periodontitis was classified according to the amount of CAL as slight (1-2 mm CAL), moderate (3-4 mm CAL) or severe (> $5 \mathrm{~mm} \mathrm{CAL}) .{ }^{19}$ Thus, healthy controls had a CAL of less than $1 \mathrm{~mm}$ with a PD of up to $3.5 \mathrm{~mm}$ (i.e., below $4 \mathrm{~mm}$ ) without any bone resorption.

The diagnosis of T2DM was based on the presence of clinical symptoms (such as polyuria, polydipsia, and weight loss) and biochemical parameters (glycaemia, glycated haemoglobin, ketoacidosis, and autoantibody status) at the outpatient unit of the Diabetology Clinics in Brno. In accordance with the American Diabetes Association guidelines, ${ }^{20}$ patients with typical symptoms were diagnosed upon finding glucose at $>11.0 \mathrm{mmol} / \mathrm{L}$ in the absence of clinical manifestations, blood glucose in venous plasma that was $\geq 7.0 \mathrm{mmol} / \mathrm{L}$ after $8 \mathrm{~h}$ of fasting, blood glucose from venous plasma $2 \mathrm{~h}$ after consuming $75 \mathrm{~g}$ glucose (oral glucose tolerance test) that was $>11.0 \mathrm{mmol} / \mathrm{L}$, or $\mathrm{HbA1c} \geq 48 \mathrm{mmol} / \mathrm{mol}$.

\section{Genetic analysis}

DNA for the genetic analysis was extracted from peripheral blood leukocytes using standard phenol/ chloroform procedures with proteinase $\mathrm{K}$.

Candidate genes that encode adipokines and their specific genetic variants were selected based on previously described associations in other populations, ${ }^{7,8}$ their possible functional impacts on the etiopathogenesis of $\mathrm{CP}$, a minor allele frequency (MAF) higher than 0.1 in the European Caucasian population studied and/or a localization that falls within the haplotype structure of the gene.

Six polymorphisms in total were analysed: ADIPOQ +276G/T (rs1501299), LEP 3`UTR A/G (rs13228377), LEP +19A/G (rs2167270), LEPR +384A/G, P1019P (rs1805096), and RETN -420C/G (rs1862513) were assayed by polymerase chain reaction (PCR) using $5^{\prime}$ nuclease TaqMan ${ }^{\circledR}$ assays (C__ 7497299_10, C__3001672_10, C__15966471_20, C___8722383_20, and C___1394112_10, respectively). Real-time PCR protocols were designed according to the manufacturer's instructions (Thermo Fisher Scientific, Waltham, USA), fluorescence was measured using the ABI PRISM 7000 Sequence Detection System (Applied Biosystems, Carlsbad, USA) and the real-time and endpoint fluorescence data were analysed using the SDS version 1.2.3 software (Applied Biosystems, Carlsbad, USA).

Although the TaqMan ${ }^{\circledR}$ assay (C__26426077_10, Thermo Fisher Scientific, Waltham, MA, USA) was available for the last SNP (ADIPOQ +45G/T (rs2241766)), this assay was not used due to incorrect genotyping results in the positive control samples. 
Thus, PCR followed by digestion with a specific restriction enzyme (RFLP-PCR) was used. PCR was carried out in a volume of $13.0 \mu \mathrm{L}$ containing $50 \mathrm{ng}$ of genomic DNA, $0.75 \mu \mathrm{M}$ of each primer (forward: 5'-GAGTCCTTTGTAGGTCCCAAC-3', reverse: 5'-CTTTCTCCCTGTGTCTAGGC-3') as previously designed Ukkola et al., ${ }^{21} 1 \mathrm{U}$ of Taq DNA polymerase (Thermo Fisher Scientific, Waltham, USA), $3.8 \mathrm{mM}$ of $\mathrm{MgCl}_{2}, 10 \times \mathrm{MgCl}_{2}$-free reaction buffer with $\left(\mathrm{NH}_{4}\right)_{2} \mathrm{SO}_{4}$ (Thermo Fisher Scientific, Waltham, MA, USA) and $0.6 \mathrm{mM}$ of deoxyribonucleoside triphosphate mix (Thermo Fisher Scientific, Waltham, USA). The reaction was carried out in a Sensoquest labcycler (Schoeller, Germany). The first step of the PCR was denaturation for $10 \mathrm{~min}$ at $95^{\circ} \mathrm{C}$ followed by 14 cycles of $95^{\circ} \mathrm{C}$ for $20 \mathrm{~s}, 64^{\circ} \mathrm{C}$ for $30 \mathrm{~s}$ and $72^{\circ} \mathrm{C}$ for $30 \mathrm{~s}$, then 20 cycles of $95^{\circ} \mathrm{C}$ for $30 \mathrm{~s}, 50^{\circ} \mathrm{C}$ for $30 \mathrm{~s}$ and $72^{\circ} \mathrm{C}$ for $30 \mathrm{~s}$. The last synthesis step was extended to $5 \mathrm{~min}$ at $72^{\circ} \mathrm{C}$. The PCR product was then incubated with the restriction enzyme SmaI (TaKaRa, Kusatsu Shiga, Japan) according to the manufacturer's instructions. The fragments were then visualized using 3.0\% agarose gel electrophoresis (constant strain $90 \mathrm{~V}$ ) with ethidium bromide. The size of the products was determined using a $50 \mathrm{bp}$ ladder (Thermo Fisher Scientific, Waltham, USA). The lengths of the fragments after digestion were $272+128 \mathrm{bp}(\mathrm{GG})$, $400+272+128$ bp (GT) and $400 \mathrm{bp}$ (TT).

\section{Plasma levels analysis}

Plasma levels of ADIPOQ, LEP and RETN were measured in a subgroup of 80 individuals. The plasma samples were prepared from venous blood collected in a tube containing 0.5 M EDTA, separated by centrifugation $\left(465 \mathrm{~g}, 4^{\circ} \mathrm{C}, 10 \mathrm{~min}\right)$, and then stored at $-70^{\circ} \mathrm{C}$ within $30 \mathrm{~min}$ after collection.

Adipokine plasma levels were determined using enzyme-linked immunosorbent assay (ELISA) kits: Adiponectin Human ELISA, High Sensitivity (Sandwich) RD191023100 (BioVendor Laboratory Medicine, Brno, Czech Republic), Leptin ELISA DEE007 (Demeditec Diagnostics GmbH, Kiel, Germany) and Human Resistin ELISA Kit ER1001-1 (Assaypro, St. Charles, USA), with VersaMax ${ }^{\mathrm{TM}}$ ELISA Microplate Reader (Molecular Devices, Sunnyvale, USA) according to the manufacturer's instructions.

\section{Statistical analysis}

The sample size of the study was statistically assessed using both a standard power calculation and a calculation of error margins for the estimates of a binomial response distribution. Due to the wide range of relative frequencies that was expected in the possible outcome response rates, the calculation of the $95 \%$ confidence margin of errors for the point estimates used $50 \%$ as the greatest demand for the sample size reference value. ${ }^{22}$ Assuming this, the sample size for all three cohorts $(\mathrm{HC}=$ non-periodontitis healthy controls, $\mathrm{H}+\mathrm{CP}=$ healthy individuals with chronic periodontitis, $\mathrm{T} 2 \mathrm{DM}+\mathrm{CP}=$ type 2 diabetes patients with chronic periodontitis) enabled point estimates of the relative frequencies with $95 \%$ error margins that were less than $11 \%$ (HC: $<9.0 \%$; $+\mathrm{CP}:<6.8 \%$; T2DM + CP: $<10.5 \%)$. The power analysis was focused on the comparisons performed by the Fisher's exact test assuming standard settings for the probability measures, i.e., an alpha level $<0.05$ and power $=0.80$. As a result, statistical comparisons between the $\mathrm{HC}$ and $\mathrm{H}+\mathrm{CP}$ cohorts maintain a detectable effect size of $+/-12 \%$, and comparisons between the $\mathrm{H}+\mathrm{CP}$ and $\mathrm{T} 2 \mathrm{DM}+\mathrm{CP}$ cohorts reach a detectable effect size of $+/-17 \%$. Both calculations assumed a $50 \%$ genotype occurrence rate as a reference value. Analyses were performed using PASS 13 software (NCSS, LLC, Kaysville, USA).

Standard descriptive statistics were applied in the analysis and are shown as the mean with standard deviations (SD) or the median with quartiles for quantitative variables and absolute or relative frequencies for categorical variables. One-way analysis of variance (ANOVA) or Kruskal-Wallis ANOVA were performed to compare the continuous variables among the groups. The allele frequencies were calculated from the observed numbers of genotypes. Based on the known functional relevance of the SNPs ADIPOQ +45G/T (rs2241766) and + 276G/T (rs1501299), Kaklamani et al. ${ }^{23}$ categorized individuals according to their $A D I P O Q$ haplogenotypes (low signallers=1=TTGG+TTGT+TGGG, intermediate signallers $=2=\mathrm{TTTT}+\mathrm{TGGT}+\mathrm{GGGG}$, high signallers $=3=$ GGGT+GGTT+TGTT) and this categorization was also used in this study. Differences in allele frequencies were compared by the Fisher-exact test, while genotype/haplogenotype frequencies and Hardy-Weinberg equilibrium (HWE) were tested using the $\chi^{2}$ test. When appropriate, a Bonferroni correction 
was used to adjust the level according to the number of independent comparisons to an overall value of 0.05 . The adjusted $p$-values are denoted as $\mathrm{p}_{\text {corr }}$. The odds ratio (OR), confidence intervals $(\mathrm{CI})$ and $\mathrm{p}$-values were also calculated. A p-value of less than 0.05 was considered to be statistically significant. All statistical analyses were performed using the Statistica v. 12 program package (StatSoft Inc., Tulsa, USA).

\section{Results}

The study group was comprised of $118 \mathrm{HC}$, $205 \mathrm{H}+\mathrm{CP}$ and $86 \mathrm{~T} 2 \mathrm{DM}+\mathrm{CP}$ patients. No patients with T2DM and healthy periodontal tissue were included in this study, and as a result, comparisons of the selected parameters were made between the $\mathrm{H}+\mathrm{CP}$ or T2DM + CP vs. HC groups (case-control study) and the $\mathrm{H}+\mathrm{CP}$ vs. T2DM + CP groups (case-case study).

Power calculations were performed separately for the mutual comparisons of different study cohorts and determined that the recruited sample size was sufficient for a confident estimation of the genotype and haplogenotype occurrence rates $(95 \%$ error margins: $\mathrm{HC}<9.0 \%, \mathrm{H}+\mathrm{CP}<6.8 \%$ and $\mathrm{T} 2 \mathrm{DM}+\mathrm{CP}$ $<10.5 \%$ ). Compared to the statistically detectable effect size (assuming $80 \%$ power of the Fisher exact test with an alpha level of $<0.05$ ) the statistically non-significant differences between the compared groups ( $\mathrm{HC}$ vs. $\mathrm{H}+\mathrm{CP}, \mathrm{H}+\mathrm{CP}$ vs. $\mathrm{T} 2 \mathrm{DM}+\mathrm{CP}$ ) were remarkably lower than the predicted detectable effects. The results of these tests are therefore consistent with the statistical power of the study.

\section{Clinical analysis}

While gender proportions were balanced in all study groups, the mean age differed between $\mathrm{H}+\mathrm{CP} / \mathrm{T} 2 \mathrm{DM}+\mathrm{CP}$ patients and $\mathrm{HC}(\mathrm{p}<0.01 / \mathrm{p}<0.05$, respectively); demographic data are given in Table 1. T2DM patients suffered from the disease for an average of $9.4 \pm 7.0$ years (standard deviation, SD). BMI was highest in the group of T2DM + CP patients, with a median value that was between overweight and obesity $\left(30 \mathrm{~kg} / \mathrm{m}^{2}\right.$ in T2DM + CP vs. $23.4 \mathrm{~kg} / \mathrm{m}^{2}$ in $\mathrm{HC}$ or $25.5 \mathrm{~kg} / \mathrm{m}^{2}$ in CP patients, $\mathrm{p}<0.01$ )

The periodontal indexes of PD and CAL and the number of teeth or sites with PD and/or a CAL $\geq 5$, as well as PI and GI, were significantly higher in healthy individuals with $\mathrm{CP}$ and diabetes patients with CP compared with the HC group $(\mathrm{p}<0.05)$.

\section{Genetic analysis}

All of the studied polymorphisms were in HWE in the control group $(p>0.05)$. Carriers of the TT genotype vs. carriers of the GG + TG genotypes for theSNP ADIPOQ

Table 1. Demographic data for the 3 study groups.

\begin{tabular}{|c|c|c|c|}
\hline \multirow{2}{*}{ Characteristics median [IQR] } & $\mathrm{HC}$ & $\mathrm{H}+\mathrm{CP}$ & $\mathrm{T} 2 \mathrm{DM}+\mathrm{CP}$ \\
\hline & $n=118$ & $n=205$ & $\mathrm{n}=86$ \\
\hline Age (years) mean $\pm S D$ & $48.3 \pm 10.8$ & $55.5 \pm 9.8$ & $67.9 \pm 9.3^{*}$ \\
\hline Sex (males, \%) & 44.9 & 39.5 & 50.0 \\
\hline $\mathrm{BMI}\left(\mathrm{kg} / \mathrm{m}^{2}\right)$ & $23.4[18.8-28.0]$ & $25.5[23.4-29.3]$ & $30.1[26.8-33.1]^{*}$ \\
\hline $\mathrm{PD}(\mathrm{mm})$ & $0.4[0.2-0.6]$ & $3.0[2.8-3.7]^{* \#}$ & $3.6[3.2-4.4]^{*}$ \# \\
\hline $\mathrm{CAL}(\mathrm{mm})$ & $0.5[0.3-0.75]$ & $4.0[3.1-4.4]^{*} \#$ & $4.7[4.1-5.6]^{* \#}$ \\
\hline Number of teeth with PD $\geq 5 \mathrm{~mm}$ & $0 \pm 0,0[0-0]$ & $8.3 \pm 6.6,5.5[4.0-12.5]^{*}$ & $10.5 \pm 6.5,11.0[5.0-15.0]^{*}$ \\
\hline Number of sites with PD $\geq 5 \mathrm{~mm}$ & $0 \pm 0,0[0-0]$ & $16.6 \pm 21.4,9.0[4.5-17.5]^{*}$ & $20.7 \pm 17.8,14.0[9.0-31.0]^{*}$ \\
\hline Number of teeth with $C A L \geq 5 \mathrm{~mm}$ & $0 \pm 0,0[0-0]$ & $14.4 \pm 6.5,16.5[7.5-19.0]^{*}$ & $15.4 \pm 5.9,16.0[12.0-19.0]^{*}$ \\
\hline Number of sites with $C A L \geq 5 \mathrm{~mm}$ & $0 \pm 0,0[0-0]$ & $34.4 \pm 23.3,31.5[15.5-45.0]^{*}$ & $38.9 \pm 20.3,41[23.0-51.0]^{*}$ \\
\hline PI & $0.3 \pm 0.1,0.3[0.2-0.3]$ & $0.9 \pm 0.6,0.7[0.4-1.4]^{*}$ & $1.2 \pm 0.5,1.3[0.7-1.5]^{*}$ \\
\hline $\mathrm{Gl}$ & $0.3 \pm 0.2,0.2[0.1-0.6]$ & $0.9 \pm 0.3,1.0[0.8-1.1]^{*}$ & $1.0 \pm 0.4,1.1[1.0-1.2]^{*}$ \\
\hline
\end{tabular}

BMI: body mass index; CAL: clinical attachment loss; GI: gingival index; $\mathrm{HC}$ : non-periodontitis healthy controls; $\mathrm{H}+\mathrm{CP}$ : healthy individuals with chronic periodontitis; IQR: interquartile range; $\mathrm{n}=$ number of subjects; PD: probing depth; PI: plaque index; SD: standard deviation; T2DM + CP: type 2 diabetes patients with chronic periodontitis. " $\mathrm{p}<0.05$ in comparison to HC; $" \mathrm{p}<0.05$ in comparison to patients with CP. Comparisons were performed by Fisher-exact test and by Kruskal-Wallis ANOVA test. 
+45G/T (rs2241766) had a lower risk of developing CP $\left(\mathrm{p}<0.01, \mathrm{p}_{\mathrm{corr}}>0.05\right)$. No significant differences were found in allele or genotype frequencies for this SNP between the $\mathrm{HC} / \mathrm{H}+\mathrm{CP}$ groups vs. the $\mathrm{T} 2 \mathrm{DM}+\mathrm{CP}$ group. The TT genotype of $A D I P O Q+45 \mathrm{G} / \mathrm{T}$ (rs2241766) occurred less frequently in the $\mathrm{H}+\mathrm{CP}$ group than in the HC group ( $\left.p=0.030, \mathrm{p}_{\text {corr }}>0.05\right)$.

Allele and genotype frequencies for the investigated SNPs in ADIPOQ +276G/T (rs1501299), LEP 3`UTR A/G (rs13228377), LEP +19A/G (rs2167270), LEPR +384A/G, P1019P (rs1805096), and RETN -420C/G (rs1862513) were not significantly different between the study groups ( $p>0.05$; Table 2$)$.

\section{Plasma levels analysis}

Adipokine plasma levels were measured in $23 \mathrm{HC}$, $20 \mathrm{H}+\mathrm{CP}$ patients and $37 \mathrm{~T} 2 \mathrm{DM}+\mathrm{CP}$ patients.
No significant differences in plasma levels of ADIPOQ, LEP or RETN were found between the different study groups (Figure 1 and 2).

In addition, adipokine plasma levels were evaluated according to BMI. Although there were no differences in the plasma levels of ADIPOQ and RETN between the normal weight $\left(\mathrm{n}=16, \mathrm{BMI}<25 \mathrm{~kg} / \mathrm{m}^{2}\right)$, overweight ( $\left.\mathrm{n}=27,25 \leq \mathrm{BMI}<30 \mathrm{~kg} / \mathrm{m}^{2}\right)$ and obesity ( $\mathrm{n}=37, \mathrm{BMI} \geq 30 \mathrm{~kg} / \mathrm{m}^{2}$ ) subgroups, the median LEP plasma levels were higher in the obese patients $(19.6$ [12.0-33.4] ng/mL) compared with the overweight $(8.5$ [5.6-15.6] ng/mL) and normal weight individuals $(1.9[0.4-9.1] \mathrm{ng} / \mathrm{mL}, \mathrm{p}<0.05$, $\mathrm{p}_{\text {corr }}>0.05, \mathrm{p}<0.01, \mathrm{p}_{\text {corr }}>0.05$, Figure 3$)$. Thus, the median of the LEP/ADIPOQ ratio was highest in the subgroup of obese patients $\left(\mathrm{p}<0.01, \mathrm{p}_{\text {corr }}>0.05\right.$, Figure 4). In the BMI $<25 \mathrm{~kg} / \mathrm{m}^{2}$ subgroup, the

Table 2. Genotype and haplogenotype frequencies and the MAF of ADIPOQ, LEP, LEPR and RETN gene polymorphisms in the 3 study groups.

\begin{tabular}{|c|c|c|c|c|c|c|c|c|c|}
\hline Gene variant & Genotype & $\begin{array}{c}\mathrm{HC} \\
\mathrm{n}=118(\%)\end{array}$ & $\chi^{2}$ & $\begin{array}{l}p \text {-value for } \\
\text { HWE in HC+ }\end{array}$ & $\begin{array}{c}H+C P \\
n=205(\%)\end{array}$ & $p$-value att & $\begin{array}{c}\text { T2DM + CP } \\
\mathrm{n}=86(\%)\end{array}$ & $\mathrm{p}$-value $\mathrm{att}^{-}$ & $p$ - value $e^{b+t}$ \\
\hline \multirow{4}{*}{$\begin{array}{l}A D I P O Q+45 G / T \\
(r s 2241766)\end{array}$} & $\mathrm{TT}$ & $105(89.0)$ & \multirow{4}{*}{0.417} & \multirow{4}{*}{0.518} & $160(78.0)$ & & 71 (82.6) & \multirow{3}{*}{0.188} & \multirow{3}{*}{0.361} \\
\hline & TG & 13 (1 1.0) & & & $41(20.0)$ & $0.030^{*}$ & 15 (14.4) & & \\
\hline & GG & $0(0.0)$ & & & $4(2.0)$ & & $0(0.0)$ & & \\
\hline & GG+TG & $13(11.0)$ & & & $44(22.0)$ & $0.009^{*}$ & $15(14.4)$ & 0.134 & 0.241 \\
\hline \multirow{3}{*}{$\begin{array}{l}A D I P O Q+276 G / T \\
(r s 1501299)\end{array}$} & GG & $56(47.5)$ & \multirow{3}{*}{0.425} & \multirow{3}{*}{0.837} & $106(51.7)$ & \multirow{3}{*}{0.429} & $39(45.3)$ & \multirow{3}{*}{0.626} & \multirow{3}{*}{0.611} \\
\hline & GT & $50(42.4)$ & & & $86(42.0)$ & & $41(47.7)$ & & \\
\hline & TT & $12(10.2)$ & & & $13(6.3)$ & & $6(7.0)$ & & \\
\hline \multirow{3}{*}{$\begin{array}{l}\text { ADIPOQ } \\
\text { haplogenotypes }\end{array}$} & 1 & $101(85.6)$ & \multirow{3}{*}{0.752} & \multirow{3}{*}{0.386} & $171(83.4)$ & \multirow{3}{*}{0.685} & 75 (87.2) & \multirow{3}{*}{0.740} & \multirow{3}{*}{0.619} \\
\hline & 2 & $17(14.4)$ & & & $33(16.1)$ & & 11 (12.8) & & \\
\hline & 3 & $0(0.0)$ & & & $1(0.5)$ & & $0(0.0)$ & & \\
\hline \multirow{3}{*}{$\begin{array}{l}\text { LEP 3'UTR A/G } \\
\text { (rs13228377) }\end{array}$} & $\mathrm{AA}$ & $29(24.6)$ & \multirow{3}{*}{2.898} & \multirow{3}{*}{0.089} & $58(28.3)$ & \multirow{3}{*}{0.514} & $25(29.1)$ & \multirow{3}{*}{0.684} & \multirow{3}{*}{0.960} \\
\hline & $A G$ & $66(56.0)$ & & & 101 (49.3) & & $43(50.0)$ & & \\
\hline & GG & $23(19.5)$ & & & $46(22.4)$ & & $18(20.9)$ & & \\
\hline \multirow{3}{*}{$\begin{array}{l}\text { LEP + 19A/G } \\
(\mathrm{rs} 2167270)\end{array}$} & GG & $42(35.6)$ & \multirow{3}{*}{3.450} & \multirow{3}{*}{0.063} & $72(35.1)$ & \multirow{3}{*}{0.217} & $34(39.5)$ & \multirow{3}{*}{0.599} & \multirow{3}{*}{0.629} \\
\hline & GA & $63(53.4)$ & & & $96(46.8)$ & & $40(46.5)$ & & \\
\hline & $\mathrm{AA}$ & 13 (1 1.0) & & & $37(18.0)$ & & $12(14.0)$ & & \\
\hline \multirow{3}{*}{$\begin{array}{l}\text { LEPR + 384A/G, } \\
\text { P1019P (rs1805096) }\end{array}$} & GG & 47 (39.8) & \multirow{3}{*}{0.001} & \multirow{3}{*}{0.986} & $82(40.0)$ & \multirow{3}{*}{0.393} & $30(34.9)$ & & \\
\hline & GA & $55(46.6)$ & & & $84(41.0)$ & & $45(52.3)$ & 0.713 & 0.170 \\
\hline & $\mathrm{AA}$ & $16(13.6)$ & & & $39(19.0)$ & & $11(12.8)$ & & \\
\hline & $\mathrm{CC}$ & $55(46.6)$ & & & 99 (48.3) & & 48 (55.8) & & \\
\hline $\begin{array}{l}\text { RETN -420C/G } \\
(\mathrm{rs} 1862513)\end{array}$ & CG & $51(43.2)$ & 0.002 & 0.966 & $86(42.0)$ & 0.958 & $29(33.7)$ & 0.371 & 0.417 \\
\hline & GG & $12(10.2)$ & & & $20(9.8)$ & & $9(10.5)$ & & \\
\hline
\end{tabular}

ADIPOQ: adiponectin; HC: non-periodontitis healthy controls; $H+C P$ : healthy individuals with chronic periodontitis; LEP: leptin; LEPR: leptin receptor; $n$ : number of subjects; RETN: resistin; T2DM + CP: type 2 diabetes patients with chronic periodontitis. ${ }^{\dagger}$ Analysis was performed by

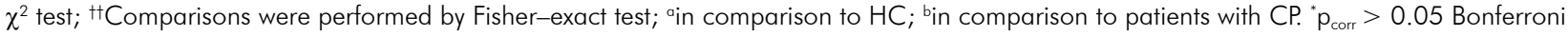
correction was applied. ADIPOQ haplogenotypes (rs2241766/rs 1501299): low signallers=1 = TTGG+TTGT+TGGG, intermediate signallers $=2=$ TTTT + TGGT + GGGG, high signallers $=3=$ GGGT + GGTT + TGTT. 
Median; Box 25\%-75\%; Whisker: non-outlier range

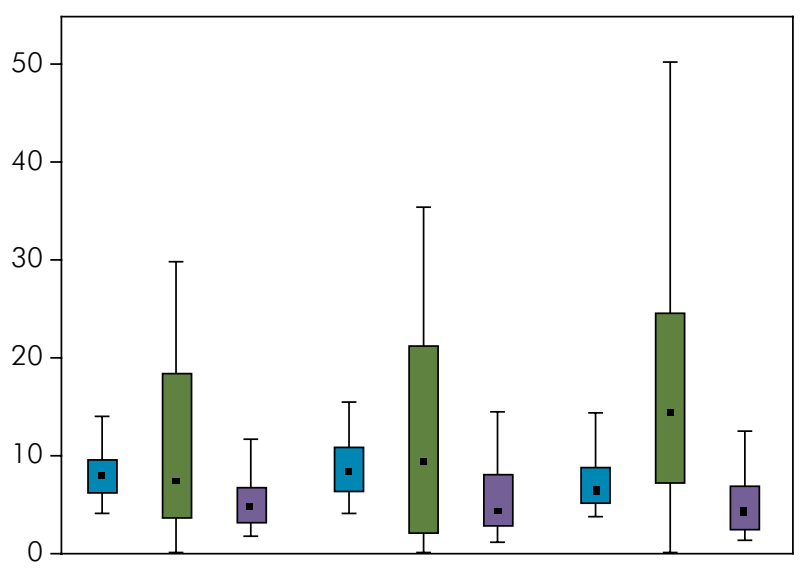

$\mathrm{HC}$

$\mathrm{T} 2 \mathrm{DM}+\mathrm{CP}$

ADIPOQ levels $\mu \mathrm{g} / \mathrm{mL} \mathrm{p}=0.056$

$\square$ LEP level $\mathrm{ng} / \mathrm{ML} \mathrm{p}=0.190$

- RETN levels $\mathrm{ng} / \mathrm{mL} \mathrm{p}=0.649$

$\mathrm{HC}$ : non-periodontitis healthy controls; $\mathrm{H}+\mathrm{CP}$ : healthy individuals with chronic periodontitis;T2DM + CP: type 2 diabetes patients with chronic periodontitis. Comparisons were performed by Kruskal-Wallis ANOVA test.

Figure 1. Plasma levels of ADIPOQ, LEP and RETN in 80 individuals $(23 \mathrm{HC}, 20 \mathrm{H}+\mathrm{CP}$, and $37 \mathrm{~T} 2 \mathrm{DM}+\mathrm{CP})$.

Median; Box 25\%-75\%; Whisker: non-outlier range

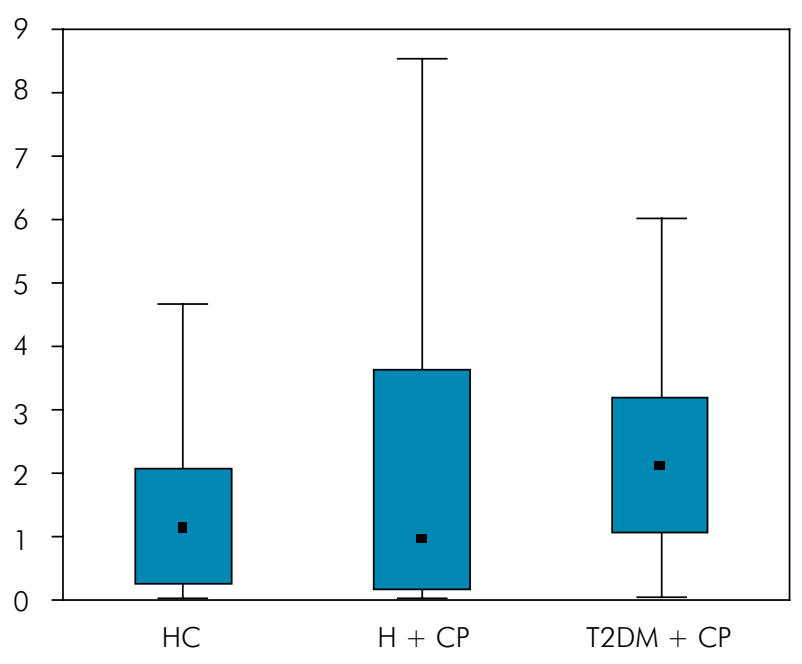

LEP/ADOPQ ratio $\mathrm{p}=0.054$

HC: non-periodontitis healthy controls; $\mathrm{H}+\mathrm{CP}$ : healthy individuals with chronic periodontitis; T2DM + CP: type 2 diabetes patients with chronic periodontitis. Comparisons were performed by Kruskal-Wallis ANOVA test.

Figure 2. $L E P / A D I P O Q$ ratios in 80 individuals $(23 \mathrm{HC}$, $20 \mathrm{H}+\mathrm{CP}$, and $37 \mathrm{~T} 2 \mathrm{DM}+\mathrm{CP})$.

Median; Box 25\%-75\%; Whisker: non-outlier range

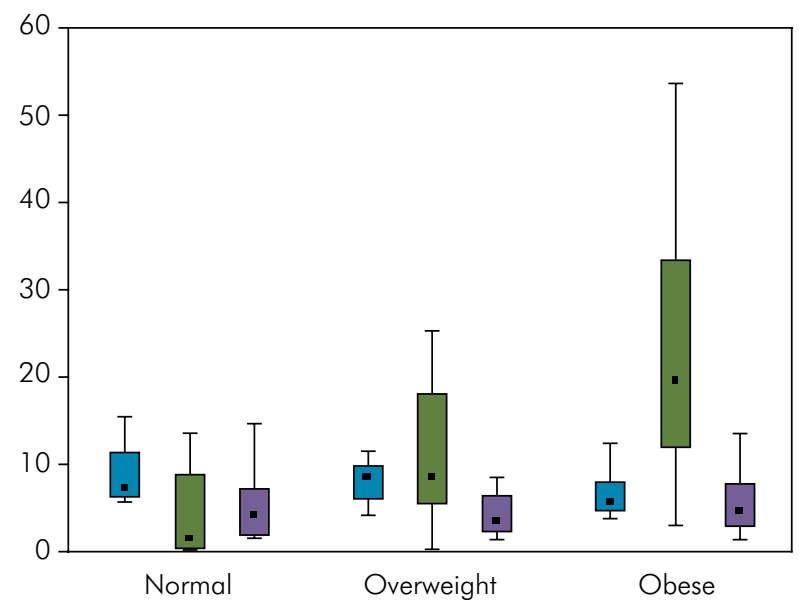

ADIPOQ levels $\mu \mathrm{g} / \mathrm{mL} \mathrm{p}=0.093$

- LEP level ng/ML $p<0.001, p_{\text {corr }}>0.05$

- RETN levels $\mathrm{ng} / \mathrm{mL} p=0.449$

$\mathrm{HC}$ : non-periodontitis healthy controls; $\mathrm{H}+\mathrm{CP}$ : healthy individuals with chronic periodontitis; T2DM + CP: type 2 diabetes patients with chronic periodontitis. Comparisons were performed by Kruskal-Wallis ANOVA test. Bonferroni correction was applied $\left(\mathrm{p}_{\text {corr }}\right)$.

Figure 3. Plasma levels of ADIPOQ, LEP and RETN in 3 groups according to $\mathrm{BMI}$ in 80 individuals.

Median; Box 25\%-75\%; Whisker: non-outlier range

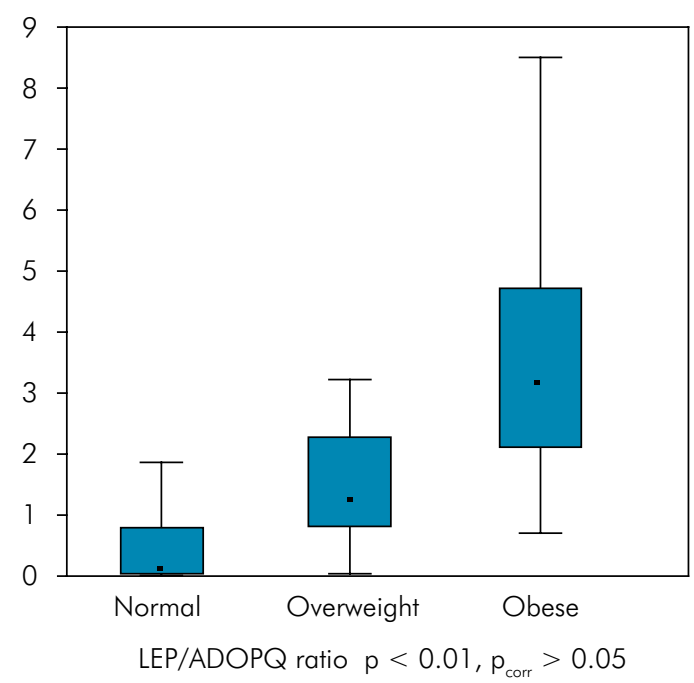

$\mathrm{HC}$ : non-periodontitis healthy controls; $\mathrm{H}+\mathrm{CP}$ : healthy individuals with chronic periodontitis; T2DM + CP: type 2 diabetes patients with chronic periodontitis. Comparisons were performed by Kruskal-Wallis ANOVA test. Bonferroni correction was applied ( $\left.p_{\text {corr }}\right)$.

Figure 4. $L E P / A D I P O Q$ ratios of 3 groups according to $B M I$ in 80 individuals. 
T2DM + CP patients (7.9 [1.6-25.1] ng/mL) had similar median LEP plasma levels to the $\mathrm{H}+\mathrm{CP}$ individuals $(0.4[0.3-8.9] \mathrm{ng} / \mathrm{mL})(\mathrm{p}=0.073)$, while differences were found in the median of the LEP/ADIPOQ ratio between these patients $(0.16$ [0.05-1.14] in the $\mathrm{T} 2 \mathrm{DM}+\mathrm{CP}$ group vs. $0.06[0.04-0.81]$ in the $\mathrm{H}+\mathrm{CP}$ group, $\left.p=0.035, p_{\text {corr }}>0.05\right)$. However, these results may be affected by the low number of subjects included in the individual subgroups.

Adipokine plasma levels were independent of individual ADIPOQ, LEP, LEPR or RETN genotypes and haplogenotypes ( $p>0.05$; Table 3 ). Nevertheless, lower levels of low density lipoprotein (LDL) were found in the carriers of the TT genotype of the SNP $A D I P O Q+45 \mathrm{G} / \mathrm{T}$ (rs2241766) than in other groups $(p<0.05)$, especially in the subgroup of T2DM patients $\left(\mathrm{p}<0.01, \mathrm{p}_{\text {corr }}>0.05\right.$, data not shown).

\section{Discussion}

Although the link between CP, T2DM and/or obesity is not fully understood, ${ }^{4}$ adipokines could

Table 3. Selected gene variants and adipokine plasma levels in 80 individuals.

\begin{tabular}{|c|c|c|c|c|}
\hline Gene variant & Genotype & $\mathrm{n}$ & $\begin{array}{c}\text { Plasma levels median } \\
\text { [IQR] }\end{array}$ & $p$-value \\
\hline & & & $\mathrm{ADIPOQ} \mu \mathrm{g} / \mathrm{mL}$ & \\
\hline \multirow{3}{*}{$A D I P O Q+45 G / T(r s 2241766)$} & TT & 67 & 7.78 [5.70-9.95] & \multirow{3}{*}{0.224} \\
\hline & TG & 12 & 6.09 [5.54-8.20] & \\
\hline & GG & 1 & 10.51 [10.51-10.51] & \\
\hline \multirow{3}{*}{$A D I P O Q+276 G / T(r s 1501299)$} & GG & 34 & $7.53[5.66-9.42]$ & \multirow{3}{*}{0.946} \\
\hline & GT & 41 & $7.41[5.71-10.51]$ & \\
\hline & $\mathrm{TT}$ & 5 & $7.13[6.38-8.15]$ & \\
\hline \multirow{4}{*}{ ADIPOQ haplogenotypes } & 1 & 68 & $7.59[5.71-9.87]$ & \multirow{3}{*}{0.327} \\
\hline & 2 & 11 & $6.19[5.25-7.79]$ & \\
\hline & 3 & 1 & $10.51[10.51-10.51]$ & \\
\hline & & & $\mathrm{LEP} \mathrm{ng} / \mathrm{mL}$ & \\
\hline \multirow{3}{*}{ LEP 3’UTR A/G (rs13228377) } & AA & 22 & $9.12[5.46-15.58]$ & \multirow{3}{*}{0.408} \\
\hline & AG & 45 & $12.35[5.03-19.62]$ & \\
\hline & GG & 13 & $15.48[6.96-26.21]$ & \\
\hline \multirow{3}{*}{$L E P+19 A / G(r s 2167270)$} & GG & 33 & $8.88[5.46-21.11]$ & \multirow{3}{*}{0.225} \\
\hline & GA & 39 & $12.88[4.55-25.36]$ & \\
\hline & $A A$ & 8 & $18.40[10.23-27.16]$ & \\
\hline \multirow{4}{*}{ LEPR + 384A/G, P1019P (rs 1805096$)$} & GG & 26 & $8.04[2.39-14.61]$ & \multirow{3}{*}{1.000} \\
\hline & GA & 44 & $14.44[7.65-25.41]$ & \\
\hline & $\mathrm{AA}$ & 10 & $9.71[1.95-15.58]$ & \\
\hline & & & RETN ng/mL & \\
\hline \multirow{3}{*}{ RETN -420C/G (rs 1862513) } & $\mathrm{CC}$ & 41 & $3.64[2.35-6.79]$ & \multirow{3}{*}{0.117} \\
\hline & CG & 27 & $4.88[3.25-6.57]$ & \\
\hline & GG & 12 & $6.25[3.64-8.30]$ & \\
\hline
\end{tabular}

ADIPOQ: adiponectin; $H C$ : non-periodontitis healthy controls; $H+C P$ : healthy individuals with chronic periodontitis; IQR:

interquartile range; LEP: leptin; LEPR: leptin receptor; $n$ : number of subjects: RETN: resistin; T2DM + CP: type 2 diabetes patients with chronic periodontitis. ADIPOQ haplogenotypes (rs2241766/rs 1501299): low signallers=1 =TTGG+TTGT+TGGG; intermediate signallers =2 =TTTT + TGGT + GGGG; high signallers=3=GGGT + GGTT+TGTT

Comparisons were performed by Kruskal-Wallis ANOVA test. 
represent a mechanism that influences the impact of periodontitis on systemic diseases. ${ }^{24} \mathrm{~A}$ review by Ogawa et al. ${ }^{25}$ described the role of the major adipokines and their associations with the pathogenesis of periodontitis in T2DM. Obesity may also modulate the systemic and periodontal levels of adipokines in favour of a pro-inflammatory state that is independent of periodontal therapy. ${ }^{26}$

ADIPOQ is a cellular hormone that plays a role in controlling the homeostasis of glucose, energy and lipid metabolism and is a key regulator of the innate immune system. ${ }^{27}$ Chronic low-grade inflammation and oxidative stress during obesity have been shown to downregulate $A D I P O Q$ gene and protein expression. ${ }^{28}$ Moreover, an LEP/ADIPOQ imbalance may be an important marker for an elevated risk of developing abdominal obesity. ${ }^{29}$ LEP, which is an obesity-regulatory hormone, is encoded by the LEP gene ("obese" gene). LEP interacts with LEPR, which leads to the regulation of appetite, control of the body's energy expenditure and maintenance of bone mass and can reduce adipose tissue inflammation. LEP has a regulatory role in the interplay between energy metabolism and the immune system and is a cornerstone in the new field of immunometabolism. Therefore, Pérez-Pérez et al. ${ }^{30}$ suggested that LEP and LEPR should be considered as markers of inflammation and immune activation in the intersection of the innate-adaptive systems and as possible targets for intervention. A study by Nokhbehsaim et al. ${ }^{31}$ demonstrated that LEP negatively interferes with the regenerative capacity of PDL cells, which suggests that LEP has a pathomechanistic link between obesity and compromised periodontal healing. A previous study also found significantly elevated levels of LEP in the plasma of patients with aggressive periodontitis compared with non-periodontitis individuals in a Chinese population. ${ }^{32}$

In humans, RETN is predominantly secreted by macrophages rather than by adipocytes. ${ }^{33}$ RETN plays a role as a mediator of insulin resistance and modulates inflammation in chronic periodontal disease. Increased serum levels of RETN were found with periodontal inflammation, which indicates a potential inflammatory role in periodontitis. ${ }^{8}$ Increased RETN serum levels were also significantly associated with periodontal condition and there was also a trend towards decreased levels of ADIPOQ in subjects with periodontitis in a Japanese population. ${ }^{34}$ Saito et al..$^{35}$ concluded that increased RETN serum levels in middle-aged Japanese women with periodontitis may affect their systemic health. RETN levels in patients with $\mathrm{CP}$ and systemic inflammatory disorders, such as diabetes, obesity, or rheumatoid arthritis, were not significantly higher than the levels in patients diagnosed with CP alone. ${ }^{36}$

Similar to the studies by Sete et al. ${ }^{37}$ and Mendoza-Azpur et al., ${ }^{38}$ this study found no significant differences in the circulating levels of ADIPOQ, LEP or RETN between the $\mathrm{CP}$ and HC groups. Furthermore, higher median LEP plasma levels were found among participants with normal weight in the T2DM + CP group when compared to the $\mathrm{H}+\mathrm{CP}$ group (though this difference was not significant after correction for multiple comparisons), which corresponds to the differences in the median LEP/ADIPOQ ratio found between these patients. It appears that diabetes status may affect the levels of these adipokines independent of weight.

Regardless of periodontal status, LEP plasma levels were significantly higher in obese patients than in the overweight or normal weight individuals, and thus the median of the LEP/ADIPOQ ratio was highest in the subgroup of obese patients in our study. These findings are in line with the results presented by López-Jaramillo et al., ${ }^{39}$ however, they must be interpreted with caution due to the number of subjects included in these comparisons.

The SNP ADIPOQ +45C/T (rs2241766) that is located in exon 2 results in a synonymous Gly15Gly change and is relatively close to exon-intron boundary. ${ }^{40}$ Thus, this polymorphism may affect splicing and modify the expression of the gene. ${ }^{41}$ In the study by Yang et al., ${ }^{42}$ the mRNA levels of the $G$ allele were consistently higher than those of the $\mathrm{T}$ allele in omental adipose tissue. Nevertheless, the mean plasma levels of ADIPOQ were similar between individuals with different $A D I P O Q+45 C / T$ (rs2241766) genotypes..$^{40}$ In line with this result, no significant association was found between ADIPOQ plasma levels and ADIPOQ +45C/T 
(rs2241766) gene variants. Furthermore, we found that plasma levels of ADIPOQ were similar between carriers of different haplogenotypes that consisted of the SNPs ADIPOQ +45C/T (rs2241766) and +276C/T (rs1501299). In contrast, Jang et al. ${ }^{43}$ previously suggested that subjects carrying the TG haplotype $A D I P O Q+45 \mathrm{C} / \mathrm{T}$ (rs2241766) and +276C/T (rs1501299) had significantly lower levels of circulating ADIPOQ compared with non-TG carriers in both normal weight and overweight-obese individuals. We conclude that the possible association between the SNP ADIPOQ $+45 \mathrm{C} / \mathrm{T}$ (rs2241766) and CP may be a consequence of linkage between this polymorphism and another functionally consequential gene variant. It is not clear why there were no differences in the frequencies of the SNP ADIPOQ +45C/T (rs2241766) between the $\mathrm{HC}$ and T2DM groups and/or the H + CP and T2DM groups. One possibility is that patients with T2DM are not likely to be genetically predisposed to $\mathrm{CP}$ by a gene variant linked to the SNP ADIPOQ +45C/T (rs2241766) as they can develop $\mathrm{CP}$ as a consequence of hyperglycaemia or other pathophysiological mechanisms that are separate from adipokines.

Our results are in contrast to both of the previous studies that focused on ADIPOQ and RETN gene variability in patients with $\mathrm{CP}$ and T2DM/ obesity. ${ }^{7,8}$ These divergent results may be caused by inter-individual variability between populations. For instance, the $A D I P O Q+45 \mathrm{C} / \mathrm{T}$ (rs2241766) minor allele frequency (MAF, G allele) in the Czech population was $8.4 \%$, while the MAF recorded in the study of a Japanese population was $31.4 \%{ }^{7}$ both results are in line with frequencies reported for European or East Asian populations in the NCBI SNP database (https://www.ncbi.nlm.nih.gov/projects/SNP/ snp_ref.cgi?rs=2241766). The second reason for the discrepancies between these studies may be the small number of subjects enrolled, especially in the patient group. Only 43 patients with T2DM and CP were selected in the preliminary study of a Japanese population ${ }^{7}$ and the RETN gene variant was only analysed in 90 participants that were then divided into three subgroups (non-obese non-periodontitis, non-obese periodontitis, obese periodontitis) from the Indian population, ${ }^{8}$ which may limit the statistical power of these studies.
The main limitation of our study is that the subgroup of T2DM patients without periodontal disease could not be included as all of the diabetes patients suffered from different severities of periodontitis. However, while the size of our cohort ( $\mathrm{n}=409$ ) was relatively small, it was still several times larger than the study populations of the two previous studies that investigated individual adipokine gene variability in patients with known periodontal status (43 Japanese patients/90 Indian participants). ${ }^{78}$ Unfortunately, we could only analyse plasma levels of the three adipokines, and did not measure salivary/GCF adipokine levels in our patients. Importantly, our study is the first to explore this issue in a Caucasian population, and we can claim a high degree of homogeneity in the study population because the participants were collected from a pool of patients of Czech-Caucasian descent from South Moravia.

\section{Conclusions}

The association of ADIPOQ and the LEP/ADIPOQ ratio with $\mathrm{T} 2 \mathrm{DM}$ and $\mathrm{CP}$ was not statistically significant, and the plasma levels of all of the studied adipokines (ADIPOQ, LEP, and RETN) were independent of genetic profiles. Nevertheless, the TT genotype of the SNP ADIPOQ +45C/T (rs2241766) was associated with a lower risk of developing $C P$. Linkage analysis of this SNP with other gene variants in $A D I P O Q$ and their subsequent functional characterization and effects on gene expression should be further investigated. We suggest that the use of larger study populations across different ethnic background is required to clarify the association between adipokine polymorphisms, adipokine levels and their impact on disease.

\section{Acknowledgements}

This study was supported by a grant from The Czech Science Foundation (GACR) GB14-37368G, the projects MUNI/A/1008/2017 and MUNI/A/1546/2018, the project AZV NV16-28462A and funds from the Faculty of Medicine of Masaryk University that were awarded to the junior researcher Petra Borilova Linhartova. 
Borilova Linhartova P, Janos J, Poskerova H, Kavrikova D, Fassmann A, Dusek L et al.

\section{References}

1. Kornman KS. Mapping the pathogenesis of periodontitis: a new look. J Periodontol. 2008 Aug;79(8 Suppl):1560-8. https://doi.org/10.1902/jop.2008.080213

2. Mendes L, Azevedo NF, Felino A, Pinto MG. Relationship between invasion of the periodontium by periodontal pathogens and periodontal disease: a systematic review. Virulence. 2015;6(3):208-15. https://doi.org/10.4161/21505594.2014.984566

3. Bascones-Martínez A, González-Febles J, Sanz-Esporrín J. Diabetes and periodontal disease. Review of the literature. Am J Dent. 2014 Apr;27(2):63-7.

4. Winning L, Linden GJ. Periodontitis and systemic disease: association or causality? Curr Oral Health Rep. 2017;4(1):1-7. https://doi.org/10.1007/s40496-017-0121-7

5. Nokhbehsaim M, Keser S, Nogueira AV, Cirelli JA, Jepsen S, Jäger A, et al. Beneficial effects of adiponectin on periodontal ligament cells under normal and regenerative conditions. J Diabetes Res. 2014;2014:796565. https://doi.org/10.1155/2014/796565

6. Nishimura F, Iwamoto Y, Mineshiba J, Shimizu A, Soga Y, Murayama Y. Periodontal disease and diabetes mellitus: the role of tumor necrosis factor-alpha in a 2-way relationship. J Periodontol. 2003 Jan;74(1):97-102. https://doi.org/10.1902/jop.2003.74.1.97

7. Damrongrungruang T, Ogawa H, Hori-Matsumoto S, Minagawa K, Hanyu O, Sone H, et al. Correlation between SNP genotypes and periodontitis in Japanese type II diabetic patients: a preliminary study. Odontology. 2015 May;103(2):233-40. https://doi.org/10.1007/s10266-014-0171-4

8. Patel SP, Raju PA. Resistin in serum and gingival crevicular fluid as a marker of periodontal inflammation and its correlation with single-nucleotide polymorphism in human resistin gene at -420. Contemp Clin Dent. 2013 Apr;4(2):192-7. https://doi.org/10.4103/0976-237X.114878

9. Akram Z, Abduljabbar T, Abu Hassan MI, Javed F, Vohra F. Cytokine profile in chronic periodontitis patients with and without obesity: a systematic review and meta-analysis. Dis Markers. 2016;2016:4801418. https://doi.org/10.1155/2016/4801418

10. Zimmermann GS, Bastos MF, Dias Gonçalves TE, Chambrone L, Duarte PM. Local and circulating levels of adipocytokines in obese and normal weight individuals with chronic periodontitis. J Periodontol. 2013 May;84(5):624-33. https://doi.org/10.1902/jop.2012.120254

11. Zhu J, Guo B, Gan X, Zhang L, He Y, Liu B, et al. Association of circulating leptin and adiponectin with periodontitis: a systematic review and meta-analysis. BMC Oral Health. 2017 Jun;17(1):104. https://doi.org/10.1186/s12903-017-0395-0

12. Thanakun S, Izumi Y. Effect of periodontitis on adiponectin, $C$-reactive protein, and immunoglobulin $G$ against Porphyromonas gingivalis in Thai people with overweight or obese status. J Periodontol. 2016 May;87(5):566-76. https://doi.org/10.1902/jop.2015.150583

13. Kanoriya D, Pradeep AR, Mallika A, Singhal S, Garg V. Correlation of crevicular fluid and serum levels of retinol-binding protein 4 and leptin in chronic periodontitis and obesity. Clin Oral Investig. 2017 Sep;21(7):2319-25. https://doi.org/10.1007/s00784-016-2025-7

14. Devanoorkar A, Kathariya R, Guttiganur N, Gopalakrishnan D, Bagchi P. Resistin: a potential biomarker for periodontitis influenced diabetes mellitus and diabetes induced periodontitis. Dis Markers. 2014;2014:930206. https://doi.org/10.1155/2014/930206

15. Williams RC, Skelton AJ, Todryk SM, Rowan AD, Preshaw PM, Taylor JJ. Leptin and pro-inflammatory stimuli synergistically upregulate MMP-1 and MMP-3 secretion in human gingival fibroblasts. PLoS One. 2016 Feb;11(2):e0148024. https://doi.org/10.1371/journal.pone.0148024

16. Silness J, Löe H. Periodontal disease in pregnancy. II. Correlation between oral hygiene and periodontal condition. Acta Odontol Scand. 1964 Feb;22(1):121-35. https://doi.org/10.3109/00016356408993968

17. Löe H. The gingival index, the plaque index and the retention index systems. J Periodontol. 1967 Nov-Dec;38(6 Part II):610-6. https://doi.org/10.1902/jop.1967.38.6_part2.610

18. Armitage GC. Development of a classification system for periodontal diseases and conditions. Ann Periodontol. 1999 Dec;4(1):1-6. https://doi.org/10.1902/annals.1999.4.1.1

19. Wiebe CB, Putnins EE. The periodontal disease classification system of the American Academy of Periodontology: an update. J Can Dent Assoc. 2000 Dec;66(11):594-7.

20. American Diabetes Association. Standards of medical care in diabetes - 2016. Diabetes Care. 2016;39(Suppl 1):S4-5. https://doi.org/10.2337/dcl6-S003

21. Ukkola O, Ravussin E, Jacobson P, Siöström L, Bouchard C. Mutations in the adiponectin gene in lean and obese subjects from the Swedish obese subjects cohort. Metabolism. 2003 Jul;52(7):881-4. https://doi.org/10.1016/S0026-0495(03)00074-X

22. Chow SC, Shao J, Wang H. Sample size calculations in clinical research. New York: Marcel Dekker; 2003.

23. Kaklamani VG, Sadim M, Hsi A, Offit K, Oddoux C, Ostrer H, et al. Variants of the adiponectin and adiponectin receptor 1 genes and breast cancer risk. Cancer Res. 2008 May;68(9):3178-84. https://doi.org/10.1158/0008-5472.CAN-08-0533

24. Deschner J, Eick S, Damanaki A, Nokhbehsaim M. The role of adipokines in periodontal infection and healing. Mol Oral Microbiol. 2014 Dec;29(6):258-69. https://doi.org/10.1111/omi.12070 
- Adipokine gene variability and plasma levels in patients with chronic periodontitis - a case-control study

25. Ogawa H, Damrongrungruang T, Hori S, Nouno K, Minagawa K, Sato M, et al. Effect of periodontal treatment on adipokines in type 2 diabetes. World J Diabetes. 2014 Dec;5(6):924-31. https://doi.org/10.4239/wid.v5.i6.924

26. Gonçalves TE, Zimmermann GS, Figueiredo LC, Souza MC, da Cruz DF, Bastos MF, et al. Local and serum levels of adipokines in patients with obesity after periodontal therapy: one-year follow-up. J Clin Periodontol. 2015 May;42(5):431-9. https://doi.org/10.1111/jcpe.12396

27. Luo Y, Liu M. Adiponectin: a versatile player of innate immunity. J Mol Cell Biol. 2016 Apr;8(2):120-8. https://doi.org/10.1093/imcb/miw012

28. Phillips SA, Kung JT. Mechanisms of adiponectin regulation and use as a pharmacological target. Curr Opin Pharmacol. 2010 Dec;10(6):676-83. https://doi.org/10.1016/i.coph.2010.08.002

29. Engin A. Adiponectin-resistance in obesity. Adv Exp Med Biol. 2017;960:415-41. https://doi.org/10.1007/978-3-319-48382-5_18

30. Pérez-Pérez A, Vilariño-García T, Fernández-Riejos P, Martín-González J, Segura-Egea JJ, Sánchez-Margalet V. Role of leptin as a link between metabolism and the immune system. Cytokine Growth Factor Rev. 2017 Jun;35:71-84. https://doi.org/10.1016/i.cytogfr.2017.03.001

31. Nokhbehsaim M, Keser S, Nogueira AV, Jäger A, Jepsen S, Cirelli JA, et al. Leptin effects on the regenerative capacity of human periodontal cells. Int J Endocrinol. 2014;2014:180304. https://doi.org/10.1155/2014/180304

32. Shi D, Liu YY, Li W, Zhang X, Sun XJ, Xu L, et al. Association between plasma leptin level and systemic inflammatory markers in patients with aggressive periodontitis. Chin Med J (Engl). 2015 Feb;128(4):528-32. https://doi.org/10.4103/0366-6999.151110

33. Lazar MA. Resistin- and obesity-associated metabolic diseases. Horm Metab Res. 2007 Oct;39(10):710-6. https://doi.org/10.1055/s-2007-985897

34. Furugen R, Hayashida H, Yamaguchi N, Yoshihara A, Ogawa H, Miyazaki $H$, et al. The relationship between periodontal condition and serum levels of resistin and adiponectin in elderly Japanese. J Periodontal Res. 2008 Oct;43(5):556-62. https://doi.org/10.1111/j.1600-0765.2008.01085.x

35. Saito T, Yamaguchi N, Shimazaki Y, Hayashida H, Yonemoto K, Doi Y, et al. Serum levels of resistin and adiponectin in women with periodontitis: the Hisayama study. J Dent Res. 2008 Apr;87(4):319-22. https://doi.org/10.1177/154405910808700416

36. Akram Z, Rahim ZH, Taiyeb-Ali TB, Shahdan MS, Baharuddin NA, Vaithilingam RD, et al. Resistin as potential biomarker for chronic periodontitis: A systematic review and meta-analysis. Arch Oral Biol. 2017 Jan;73:311-20. https://doi.org/10.1016/i.archoralbio.2016.08.016

37. Sete MR, Lira Júnior R, Fischer RG, Figueredo CM. Serum adipokine levels and their relationship with fatty acids in patients with chronic periodontitis. Braz Dent J. 2015 Mar-Apr;26(2):169-74. https://doi.org/10.1590/0103-6440201300297

38. Mendoza-Azpur G, Castro C, Peña L, Guerrero ME, De La Rosa M, Mendes C, et al. Adiponectin, leptin and TNF- $\alpha$ serum levels in obese and normal weight Peruvian adults with and without chronic periodontitis. J Clin Exp Dent. 2015 Jul;7(3):e380-6. https://doi.org/10.4317/jced.52350

39. López-Jaramillo P, Gómez-Arbeláez D, López-López J, López-López C, Martínez-Ortega J, Gómez-Rodríguez A, et al. The role of leptin/adiponectin ratio in metabolic syndrome and diabetes. Horm Mol Biol Clin Investig. 2014 Apr;18(1):37-45. https://doi.org/10.1515/hmbci-2013-0053

40. Takahashi M, Arita Y, Yamagata K, Matsukawa Y, Okutomi K, Horie M, et al. Genomic structure and mutations in adipose-specific gene, adiponectin. Int J Obes Relat Metab Disord. 2000 Jul;24(7):861-8. https://doi.org/10.1038/sj.ijo.0801244

41. Cartegni L, Chew SL, Krainer AR. Listening to silence and understanding nonsense: exonic mutations that affect splicing. Nat Rev Genet. 2002 Apr;3(4):285-98. https://doi.org/10.1038/nrg775

42. Yang WS, Tsou PL, Lee WJ, Tseng DL, Chen CL, Peng CC, et al. Allele-specific differential expression of a common adiponectin gene polymorphism related to obesity. J Mol Med (Berl). 2003 Jul;81(7):428-34. https://doi.org/10.1007/s00109-002-0409-4

43. Jang Y, Chae JS, Koh SJ, Hyun YJ, Kim JY, Jeong YJ, et al. The influence of the adiponectin gene on adiponectin concentrations and parameters of metabolic syndrome in non-diabetic Korean women. Clin Chim Acta. 2008 May;391(1-2):85-90. https://doi.org/10.1016/i.cca.2008.02.011 